\title{
(2) OPEN ACCESS \\ Clinicopathological characteristics and genetic variations of uterine tumours resembling ovarian sex cord tumours
}

\author{
Shan Ye (1) , ${ }^{1,2,3}$ Jing Wu, ${ }^{1,2,3}$ Lingli Yao, ${ }^{1,2}$ Jie He $e^{1,2,3}$
}

'Department of Pathology, The First Affiliated Hospital of USTC, Division of Life Sciences and Medicine, University of Science and Technology of China, Hefei, Anhui, China

Intelligent Pathology Institute, Division of Life Sciences and Medicine, University of Science and Technology of China, Hefei, Anhui, China

${ }^{3}$ Department of Pathology, Anhui Provincial Cancer Hospital, Hefei, Anhui, China

\section{Correspondence to}

Professor Jie He, Department of Pathology, The First Affiliated Hospital of USTC, Division of Life Sciences and Medicine, University of Science and Technology of China, Hefei, Anhui, China; hejie23@ustc. edu.cn

Received 29 January 2021 Accepted 3 July 2021

\begin{abstract}
Aims To investigate the clinicopathological and molecular characteristics of uterine tumours resembling ovarian sex cord tumours (UTROSCTS) and the value of molecular diversity in the clinical diagnosis and treatment.

Methods Five patients with UTROSCT were enrolled, and their clinical data, pathological morphologies, immunophenotypes and molecular features were analysed. Fluorescence in situ hybridisation for NCOA1, NCOA2, NCOA3, JAZF1 and PHF1 and next-generation sequencing for 27 homologous recombination/repair (HRR) pathway genes were performed on five and three UTROSCT specimens, respectively.

Results All five patients were treated for abnormal uterine bleeding and grossly presented with intrauterine polyps. Under a microscope, tumour cells grew diffusely and presented a cordlike arrangement and glandular duct-like structures, with nuclei ranging from round to oval, vesicular chromatin and visible nucleoli in some cases. The mitotic count was less than 3/10 high-power fields. Immunohistochemistry showed sex cord, epithelial cell and smooth muscle cell biomarkers and diffuse, strong staining for B cell lymphoma-2 (BCL-2). NCOA1 and NCOA3 rearrangements were identified in $80 \%$ (4/5) of the cases. JAZF1 and PHF1 rearrangements were not detected in any of five patients. HRR pathway gene mutations were detected in all three patients, including FANCE, ATR and ARID1A mutations in one case each. Conclusion UTROSCT is a rare mesenchymal tumour, and biopsy specimens are easily misdiagnosed. UTROSCT diagnosis requires the combined use of biomarkers and molecular detection. BCL-2 has potential diagnostic value as a marker. UTROSCT can have mutations related to the HRR pathway, suggesting that this tumour type may be sensitive to platinum/poly (ADP-ribose) polymerase inhibitors.
\end{abstract}

\section{INTRODUCTION}

Uterine tumour resembling ovarian sex cord tumour (UTROSCT) is a rare type of tumour with unclear origins and is defined histologically by sex cordlike growth patterns, such as sheets, nests, trabeculae, cords or tubules, with/without Sertoli-like or Leydig-like components, and immunohistochemically by variable sex cord markers in addition to epithelial, myogenic and sex hormone markers. ${ }^{1-4}$ UTROSCTs are most common in perimenopausal and postmenopausal women, with an average age of approximately 50 years, and the main clinical presentation is abnormal uterine bleeding and/or abdominal pain. ${ }^{15}$ Due to the low incidence, our understanding of UTROSCT is very limited, and it is prone to misdiagnosis.

Homologous recombination/repair (HRR) is an important repair method for DNA double-strand damage to maintain the integrity of the genome and ensure the transmission of genetic information in high fidelity. HRR is a complex signalling pathway, and BRCA1 and BRCA2 are the key proteins. Mutations in HRR-related genes can cause homologous recombination deficiency (HRD) and lead to genomic instability, and tumour cells often use HRR to prevent cell apoptosis. ${ }^{6}$ However, when tumour cells develop HRD and poly (ADP-ribose) polymerase (PARP) is inhibited, a 'synthetic lethal' effect will occur, and tumours with HRD are more sensitive to platinum/PARP inhibitors. ${ }^{67}$

UTROSCTs appear to have low malignant potential. However, cases with recurrence and even metastasis to remote sites have been reported. ${ }^{7-9}$ Therefore, for patients with UTROSCT who cannot tolerate surgery or experience metastasis or recurrence, other potential treatments must be identified. This study attempted to further analyse the nature of this tumour by studying its clinicopathological characteristics and gene variations to provide a basis for clinical diagnosis and prognostic prediction.

\section{MATERIALS AND METHODS Clinical data}

Five patients aged 39-65 years who were diagnosed with UTROSCT between 2014 and 2020 were enrolled in the study. These patients sought treatment due to abnormal uterine bleeding, and pathological sections were reviewed by two senior pathologists.

\section{Immunohistochemical staining}

All specimens were fixed in $3.7 \%$ neutral formalin and embedded in paraffin, and 20 consecutive sections were generated for H\&E and immunohistochemical staining. Immunohistochemistry was performed using a BenchMark XT automated slide stainer (Roche, the USA). Four primary antibodies came in ready-to-use working solutions: cluster of differentiation 10 (CD10, rabbit monoclonal antibodies (mAb), SP67, Roche), oestrogen receptor (ER, rabbit $\mathrm{mAb}, \mathrm{SP} 1$, Roche), progesterone receptor ( $\mathrm{PR}$, rabbit $\mathrm{mAb}, 1 \mathrm{E} 2$, Roche) and smooth muscle actin (SMA, mouse mAb, 1A4, MXB Biotechnologies, Fuzhou, China). Other primary 
antibodies, against pan-cytokeratin (CKpan, mouse mAb, AE1/ mA3), epithelial membrane antigen (EMA, mouse mAb, GP1.4), B cell lymphoma-2 (BCL-2, mouse mAb, bcl/100/D5), $\alpha$-inhibin (mouse mAb, AMY82), calretinin (rabbit polyclonal antibody), steroidogenic factor-1 (SF-1, mouse mAb, OTI1H2), Wilms' tumour 1 (WT-1, mouse mAb, 6F-H12), cluster of differentiation 99 (CD99) (rabbit mAb, EP8), desmin (rabbit mAb, EP15), h-caldesmon (rabbit mAb, EP19) and antigen Ki-67 (mouse mAb, UMAB107), were purchased from ZSGB Biotech, Beijing, China. The secondary antibody was the Roche universal horseradish peroxidase-labelled antibody mixture (goat anti-mouse IgG, goat anti-mouse IgM and goat anti-rabbit). Primary antibodies were conjugated using a cocktail of enzyme-labelled secondary antibodies. Diaminobenzidine was used for colour development. Haematoxylin was used for nuclear counterstaining.

\section{Fluorescence in situ hybridisation (FISH)}

Five tumour tissue samples were subjected to FISH to identify molecular rearrangements of NCOA1, NCOA2, NCOA3, JAZF1 and PHF1 (all from Guangzhou Anbiping Pharmaceutical Technology, China). FISH was performed as described previously. ${ }^{5}$ Briefly, the unstained slides were deparaffinised, pretreated and hybridised to denatured probes. Then, after more than 6 hours of incubation at $37^{\circ} \mathrm{C}$, the slides were washed and counterstained with diamidine phenyl indole (DAPI), mounted and analysed using a Zeiss fluorescence microscope (Olympus BX51, Tokyo, Japan).

\section{Next-generation sequencing (NGS)}

Tumour tissue samples and the corresponding paracancerous tissues collected over the last 3 years from three patients with UTROSCT were subjected to multigene sequencing of $27 \mathrm{HRR}$ pathway-related genes (sequencing was completed by Shanghai Zhengu Biotechnology, China): BRCA1, BRCA2, PIK3CA, KRAS, NRAS, BRAF, ATM, ATR, BARD1, BRIP1, CHEK2, CTNNB1, FANCA, FANCC, FANCD2, FANCE, FANCF, PTEN, MRE11A, NBN, PALB2, PPP2R1A, RAD50, RAD51, RAD51C, RAD51D and ARID1A. The average sequencing depth was $3000 \mathrm{X}$, and the on-target rates were greater than $95 \%$. The obtained mutations were filtered to retain only non-synonymous mutations, stop-gain mutations, frameshift mutations and splicing mutations. The common mutations were filtered out according to the frequency in the population. Finally, the mutations that impaired protein function, based on the results of the prediction software, were retained.

\section{RESULTS}

\section{Clinical characteristics}

As shown in table 1, the ages of the patients ranged from 39 to 65 years, with a median age of 53 years. The clinical manifestations included two cases of postmenopausal vaginal bleeding (cases 2 and 3 ) and other three cases of increased menstrual bleeding and prolonged periods. B-mode ultrasound suggested hypoechoic intrauterine nodules. One patient underwent hysteroscopic electrical resection (case 4), and other four patients underwent hysterectomy and bilateral adnexectomy. In general, two patients had intramural nodules protruding into the uterine cavity; two patients had intrauterine polypoid masses with a greyish-brown section, the texture of which was soft to slightly tough, and some of the polyps were lobulated with visible borders with the myometrium; one patient had a fragmented cordlike tissue (case 4 ), and the tumour size was $1.5-5 \mathrm{~cm}$ in diameter.

\section{Histological characteristics}

Under low magnification, tumor cells were arranged in a nested, trabecular, cord, reticular (figure 1A), glandular (figure 1B), small tubular and Call-Exner body-like follicular appearance (figure 1C), consisting of epithelial-looking cells and spindleshaped cells, with scant interstitial hyaline degeneration. Under high magnification, the nuclei were oval, overlapping and without nuclear grooves, and the nucleoli were not obvious in three cases and were visible in two cases (figure 1D). The mitotic count was $0-2 / 10$ high-power fields. Borders of the myometrium

Table 1 Clinical and pathological features of five patients with UTROSCT

\begin{tabular}{|c|c|c|c|c|c|}
\hline & Case 1 & Case 2 & Case 3 & Case 4 & Case 5 \\
\hline Age & Early 50 s & Early 60 s & Early 60 s & Nearly 40 years & Nearly 40 years \\
\hline Symptoms & $\begin{array}{l}\text { Irregular vaginal bleeding in the } \\
\text { past } 2 \text { years }\end{array}$ & $\begin{array}{l}\text { Menopause for } 10 \text { years } \\
\text { and irregular vaginal } \\
\text { bleeding } 4 \text { months earlier }\end{array}$ & $\begin{array}{l}\text { Menopause for } 22 \text { years, } \\
\text { irregular vaginal bleeding } 14 \\
\text { days before admission }\end{array}$ & $\begin{array}{l}\text { Increased menstrual bleeding } \\
\text { and with the menstrual period } \\
\text { extending for half a year }\end{array}$ & $\begin{array}{l}\text { Increased menstrual } \\
\text { bleeding for more than } \\
3 \text { months }\end{array}$ \\
\hline Ultrasonic examination & $\begin{array}{l}\text { Hypoechoic area on the } \\
\text { posterior wall of the uterus } \\
\text { with protrusion into the uterine } \\
\text { cavity }\end{array}$ & $\begin{array}{l}\text { Hypoechoic protrusion on } \\
\text { right uterine wall with clear } \\
\text { boundary }\end{array}$ & Not available & Hypoechoic intrauterine nodules & $\begin{array}{l}\text { Consider endometrial } \\
\text { polyps }\end{array}$ \\
\hline General & $\begin{array}{l}\text { Intramural nodules protruding } \\
\text { into the uterine cavity, } 4.5 \mathrm{~cm} \\
\text { in diameter }\end{array}$ & $\begin{array}{l}\text { Intrauterine polypoid } \\
\text { masses, } 5 \mathrm{~cm} \text { in diameter }\end{array}$ & $\begin{array}{l}\text { Intramural nodules with } \\
\text { polypoid bulging of the } \\
\text { uterine cavity, } 4 \mathrm{~cm} \text { in } \\
\text { diameter }\end{array}$ & $\begin{array}{l}\text { Submucosal elevation, } 3 \mathrm{~cm} \text { in } \\
\text { diameter (fragment tissue) }\end{array}$ & $\begin{array}{l}\text { Polypoid masses, } 1.5 \mathrm{~cm} \\
\text { in diameter }\end{array}$ \\
\hline Surgical approach & $\begin{array}{l}\text { Hysterectomy and bilateral } \\
\text { adnexectomy }\end{array}$ & $\begin{array}{l}\text { Hysterectomy and bilateral } \\
\text { adnexectomy }\end{array}$ & $\begin{array}{l}\text { Hysterectomy and bilateral } \\
\text { adnexectomy }\end{array}$ & Electrical resection & $\begin{array}{l}\text { Hysterectomy and } \\
\text { bilateral adnexectomy }\end{array}$ \\
\hline Muscular invasion & Tonguelike infiltration & Focal infiltration & Focal infiltration & Focal infiltration & Focal infiltration \\
\hline Nucleolus & Yes & Yes & None & None & None \\
\hline Necrosis & None & None & Yes & None & None \\
\hline Mitotic count (/10 HPF) & 2 & 1 & 1 & 0 & 0 \\
\hline Comorbidities & None & Leiomyoma & Leiomyoma & Endometrial polyps & $\begin{array}{l}\text { Multiple endometrial } \\
\text { polyps }\end{array}$ \\
\hline Medical history & None & $\begin{array}{l}\text { Leiomyoma resection } 20 \\
\text { years ago }\end{array}$ & Diabetes, taking metformin & None & None \\
\hline
\end{tabular}

HPF, high-power field; UTROSCT, tumours resembling ovarian sex cord tumour. 


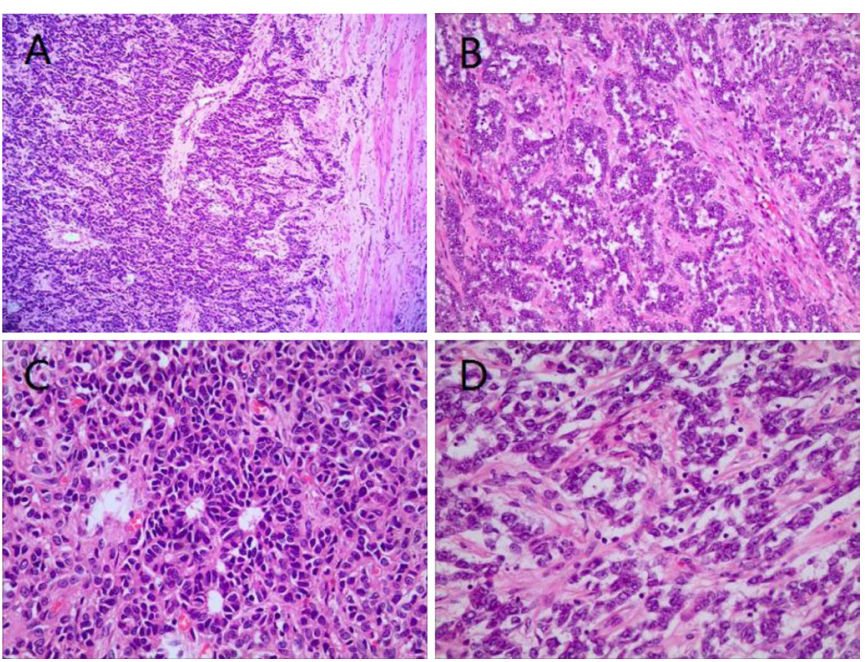

Figure 1 Microscopic characteristics of tumours resembling ovarian sex cord tumour. (A) The tumour was reticulated, and the boundary with the muscular layer was not clear, H\&E $\times 100$; (B) the tumour showed an adenoid arrangement and interstitial fibrosis, $H \& E \times 200$; (C) the tumour was arranged in a Call-Exner corpus-like pattern, H\&E $\times 200$; (D) small nucleoli were observed in some cases, $\mathrm{H} \& \mathrm{E} \times 400$.

were unclear in all five patients (figure 1), which were observed even in hysteroscopic resection specimens. One patient showed obvious tonguelike infiltration (case 1) without vascular involvement, and haemorrhage and necrosis were noted on the surface of the tumour in one case (case 3). Two patients had endometrial polyps (cases 4 and 5), and two patients had uterine leiomyomas.

\section{Immunohistochemical characteristics}

As shown in table 2, more than two sex cord markers were expressed in all five patients. The positive expression rates of $\alpha$-inhibin, WT-1, SF-1 (figure 2A), calretinin (figure 2B) and

Table 2 Immunohistochemical results of five patients with UTROSCT

\begin{tabular}{llllll}
\hline & Case 1 & Case 2 & Case 3 & Case 4 & Case 5 \\
\hline CK & $1+$ & $1+$ & $1+$ & $2+$ & $2+$ \\
WT-1 & - & - & $3+$ & - & $2+$ \\
CD99 & $2+$ & $2+$ & $2+$ & $2+$ & - \\
CR & $2+$ & $2+$ & $2+$ & - & $2+$ \\
$\alpha$-Inhibin & - & $1+$ & - & - & - \\
SF-1 & - & $2+$ & $2+$ & - & $2+$ \\
EMA & - & - & - & - & - \\
Desmin & - & $2+$ & - & $2+$ & $1+$ \\
SMA & $2+$ & $1+$ & $1+$ & $3+$ & - \\
h-Caldesmon & $2+$ & $2+$ & $2+$ & $2+$ & $1+$ \\
BCL-2 & $3+$ & $3+$ & $3+$ & $3+$ & $3+$ \\
ER & $1+$ & $1+$ & $2+$ & $3+$ & $2+$ \\
PR & $3+$ & $3+$ & $3+$ & $3+$ & $2+$ \\
\hline CD10 & $1+$ & $1+$ & $1+$ & $1+$ & - \\
\hline
\end{tabular}

'-' indicates negativity; '1+' denotes weak or focal positivity, with a number of positive cells $<25 \%$; ' $2+$ ' indicates moderate positivity, with a number of positive cells of $25 \%-75 \%$; ' $3+$ ' denotes diffuse strong positivity, with a number of positive cells $>75 \%$.

BCL-2, B cell lypmphoma-2; CD10, cluster of differentiation 10; CD99, cluster of differentiation 99; CK, cytokeratin; EMA, epithelial membrane antigen; ER, oestrogen receptor; PR, progesterone receptor; SF-1, steroidogenic factor-1; SMA, smooth muscle actin; UTROSCT, tumours resembling ovarian sex cord tumour; WT-1, Wilms' tumour 1 .
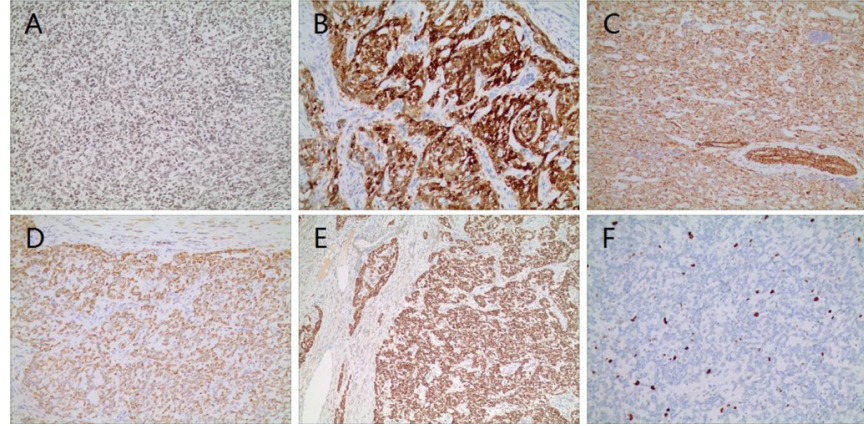

Figure 2 Immunohistochemical staining by the Envision method. (A) Steroidogenic factor-1 is positive in tumour cell nuclei $(\times 400)$; (B) calretinin was diffusely positive in tumour cell cytoplasm and nuclei (×200); (C) h-caldesmon was diffusely positive in tumour cell cytoplasm and was positive in thick-walled blood vessels in the internal control ( $\times 200)$; (D) pan-cytokeratin was diffusely positive in tumour cell cytoplasm (×100); (E) B cell lymphoma-2 (BCL-2) was diffusely positive in tumour cell cytoplasm but negative in the peripheral muscular layer and blood vessels (×200); (F) Ki-67 was sporadically positive in tumour cell cytoplasm.

CD99 were $1 / 5,2 / 5,3 / 5,4 / 5$ and $4 / 5$, respectively. All patients expressed one or more smooth muscle markers, and the positive expression rates of desmin, SMA, and h-caldesmon (figure 2C) were $3 / 5,4 / 5$ and $5 / 5$, respectively. CKpan (figure 2D), BCL-2 (figure 2E), ER and PR expressions were observed and EMA was negative in all five patients. The CD10-positive rate was $4 / 5$, and the positive rate of $\mathrm{Ki}-67$ was $5 \%-15 \%$ in all five patients (figure 2F).

\section{Molecular features}

NCOA1 (figure 3A) gene breaks were detected in cases 1, 2 and 3. NCOA3 gene breaks was detected in case 4. Case 5 did not have any of these gene breaks. NCOA2, JAZF1 (figure 3B) and PHF1 gene breaks were not detected in any of the five patients.

Somatic pathological mutations were detected in three patients. FANCE gene Exon 1 pW19X stop-gain mutation (G-A) was detected in case 4, resulting in the acquisition of a stop codon. The ATR gene Exon 9 pI710Yfs5 frameshift mutation (AT-A) was detected in case 3. The ARID1A gene Exon 1 pP21del non-frameshift mutation (CCCG-C) was detected in case 2. No suspected pathogenic germline mutations in the HRR-related pathway genes were found in the three patients.
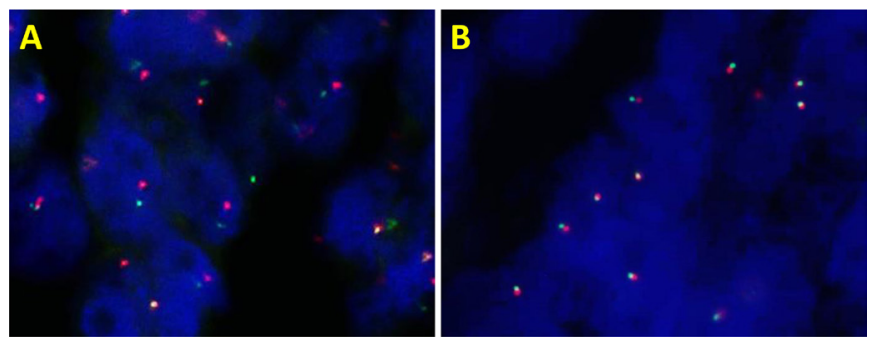

Figure 3 Fluorescence in situ hybridisation (FISH) test features of tumours resembling ovarian sex cord tumour. (A) FISH showing a separated signal for NCOA1 (case 3); (B) FISH showing no separated signal for JAZF1 (case 1). 


\section{Treatment and follow-up}

Four patients underwent hysterectomy and bilateral adnexectomy, one patient underwent hysteroscopic resection and all five patients were followed up. None of the patients received further postoperative treatment. The follow-up time was 4-72 months (average 20 months), and no recurrence or metastasis was noted.

\section{DISCUSSION}

Uterine tumours with sex cord-like elements were first proposed by Clement et al in $1976 .{ }^{10}$ Based on their biological behaviour, this type of tumour was classified into two groups. Group I is endometrial stromal tumours with foci of sex cord-like elements (sex cord elements $<50 \%$ ), which usually show recurrence and metastasis. Group II is composed predominantly or exclusively of sex cord-like elements (>50\%). They are mostly benign and generally do not recur or metastasise. In the 2003 version of the WHO classification, group II was included in the 'other' types of mesenchymal tumours, and the diagnosis was uterine sex cord-like tumour. In the 2014 version of the WHO classification, group I was included in the low-grade endometrial stromal tumours, while group II tumours were individually categorised as UTROSCT. This emphasised that only when tumours lack classic endometrial stromal tumour elements can this diagnosis be made. ${ }^{11}$

Compared with low-grade endometrial stromal tumours with sex cord-like differentiation, UTROSCT lacks the JAZF1SUZ12 (two zinc finger protein genes) fusion gene or the PHF1 rearrangement. ${ }^{12}$ Both JAZF1 and PHF1 were absent in all five of our patients, which is useful for distinguishing UTROSCT from low-grade endometrial stromal tumours with sex cordlike differentiation. In addition, UTROSCT lacks the FOXL2 mutation in adult granulosa cell tumours of the ovary and has the dicer 1, ribonuclease III mutations in Sertoli-Leydig cell tumours, although UTROSCT can express FOXL2 as detected by immunohistochemistry. ${ }^{13}$

UTROSCT may represent an independent tumour unrelated to endometrial stromal tumours and ovarian sex cord-stromal tumours. Dickson et $a l^{14}$ recently reported that UTROSCT includes NCOA2 or NCOA3 gene fusions, suggesting that UTROSCT is an independent tumour. Goebel et $a l^{5}$ also reported that UTROSCTs show NCOA2-3 gene fusions, and novel rearrangements involving NCOA1 were identified. In all, $81.8 \%(18 / 22)$ of cases showed NCOA1-3 fusions, emphasising that UTROSCT is a distinct entity and that the detection of these gene fusions is useful in differentiating this tumour from other entities. In our study, NCOA1 and NCOA3 were identified in $80 \%(4 / 5)$ of our patients, which provides strong support for the diagnosis of UTROSCT.

The immunohistochemical features of UTROSCT are the multiple phenotypes of epithelial cells, smooth muscle cells, sex cord markers and hormone receptors. ${ }^{1}$ Among the five cases reported here, at least two of the sex cord markers $\alpha$-inhibin, calretinin, SF-1, CD99 and WT-1 were positive. Among them, $\alpha$-inhibin and SF-1 are currently the most specific markers for the diagnosis of ovarian sex cord-stromal tumours. Stewart et $a l^{15}$ compared UTROSCT with other uterine tumours with sex cord differentiation and found that the sensitivity of calretinin in the diagnosis of UTROSCT was $100 \%$, the specificity was $80 \%$ and the sensitivity and specificity of SF-1 were $50 \%$ and $100 \%$, respectively. In our cases, three were positive for SF-1, which was consistent with the above reports, suggesting that sex cord differentiation is a concomitant feature in uterine tumours but is intrinsic in UTROSCT. Cytokeratin (CK) was positive, and
EMA was negative in all five cases, consistent with the traits of ovarian sex cord-stromal tumours. ${ }^{16}$ The positive expression of CK can easily lead us to misdiagnose it as an epithelial malignant tumour, especially in biopsy specimens. In these cases, EMA should be included for diagnosis.

We inadvertently found strong, diffuse BCL-2 positivity in one patient with UTROSCT, so we retrospectively performed immunohistochemistry for BCL-2 in the other four cases and surprisingly found that all tumours diffusely and strongly expressed BCL-2. In 2003, Wang et al ${ }^{17}$ also reported diffusely and strongly expressed BCL-2 in one patient with UTROSCT. This patient had a translocation on chromosomes $\mathrm{t}(4 ; 18)(\mathrm{q} 21.1 ; \mathrm{q} 21.3)$ and $\mathrm{t}(\mathrm{x} ; 6)(\mathrm{p} 22.3 ; \mathrm{q} 23.1)$, which the authors suggest is associated with the inclusion of important oncogenes such as BCL-2 and MALT1 on chromosome 18. BCL-2 antagonises cell apoptosis, ${ }^{18}$ but the mechanism is not clear. BCL-2 overexpression may have potential value in the diagnosis of UTROSCT; however, more cases need to be investigated.

The differential diagnosis included the following

1. Epithelioid leiomyoma: Epithelioid leiomyoma has similarities to UTROSCT, and both show clear boundaries, soft textures, yellow or grey cross sections, round or polygonal tumour cells and cells arranged in tufts and cords under a microscope. However, epithelioid leiomyomas are commonly associated with the transition of spindle-shaped smooth muscle cells, and they lack the UTROSCT-like sex cord-like phenotype based on immunohistochemistry.

2. Endometrial stromal sarcomas or endometrial stromal nodules with sex cord differentiation: Histologically, a typical area of an endometrial stromal tumour can always be found, such as characteristic small arteries, proliferation of endometrial stromal cells and diffusely positive CD10, while its sex cord-differentiated areas are indistinguishable from UTROSCT. When the two are difficult to distinguish, molecular detection can be performed. Endometrial stromal tumours show specific $\mathrm{t}(7 ; 17)(\mathrm{p} 15 ; \mathrm{q} 21)$ translocations, resulting in JAZF1-SUZ12 gene fusion.

3. Endometrial cancer (epithelial malignant tumour): In biopsy specimens, the epithelioid-like structure of UTROSCT, broad-spectrum CK positivity and clinical history of abnormal vaginal bleeding can easily lead us to misdiagnose it as an epithelial malignant tumour, but misdiagnosis can be avoided with the careful observation of the mitotic figures and nuclear heterogeneity.

Among these five patients with UTROSCT, two fertile patients also had endometrial polyps, including one case of multiple polyps, and two menopausal patients also had multiple uterine leiomyomas. Is the occurrence of UTROSCT related to a high oestrogen level? Some patients with UTROSCT have had breast cancer and tamoxifen treatment histories, so more clinical data need to be accumulated. ${ }^{19} 20$

For patients with UTROSCT, surgical intervention is an effective treatment, and the prognosis of most patients is good. However, in a study with long-term follow-up (average 39 months) published in 2017, 23.5\% (8/34) of the patients had recurrence and metastasis. ${ }^{21}$ Therefore, UTROSCT has obvious malignant potential, with no reliable prognostic factor in histology. The adjuvant treatment approaches for these eight patients with recurrence were different, and eventually, three patients died of this tumour. It has recently been found that UTROSCT has the recurrent fusion of NCOA2 or NCOA3, its partner genes are ESR1 and GREB $1^{14}$ and recurrence has been associated with $G R E B 1,5$ which underscores the possible value of molecular detection in predicting prognosis. Therefore, for 
patients with UTROSCT who cannot tolerate surgery or experience metastasis or recurrence, choosing an effective treatment is a new challenge. However, there is very little evidence to aid decision making.

HRR is an important repair method for DNA doublestrand damage, and defects in this pathway usually lead to tumorigenesis. ${ }^{6}$ HRD has been observed in some patients with ovarian cancer or breast cancer, ${ }^{22}$ especially in patients with high-grade ovarian serous carcinoma, ${ }^{23}$ who are sensitive to platinum-containing drugs and PARP inhibitors. ${ }^{6}{ }^{24} \mathrm{HRR}$ involves multiple steps; in addition to BRCA1/2, mutations in other HRR-related genes can also cause HRD and lead to genome instability. ${ }^{25}$ Pellegrino et $a l^{26}$ performed germline and systemic mutation sequencing of 13 HRR-related genes in 390 cases of ovarian cancer and found that patients with germline or systemic HRR-related gene mutations were highly correlated with platinum-based treatment sensitivity and good prognosis. For this reason, some researchers put forward the concept of 'BRCAness', which describes HRD that does not have BRCA mutations but has a phenotype similar to $B R C A$ mutation tumours. ${ }^{27}$ Therefore, the detection of HRD needs to integrate the detection of BRCA1/2 and other HRR-related genes to more effectively screen the population for platinum/ PARP inhibitors.

With the key advances in NGS technology, NGS has expanded our understanding of HRD and related gene instability in more tumour types. To understand whether these drugs can benefit patients with UTROSCT, we detected 27 HRR pathway-related genes by NGS, and the results showed that suspected pathogenic somatic mutations were detected in all three of patients, including FANCE, ATR and ARID1A. ATR kinase is a RAD3-related protein that can directly phosphorylate the protein encoded by the tumour suppressor gene p53 and cell cycle regulatory proteins; ATR and its associated signalling pathways are critical to genome stability and the occurrence and development of various tumours. ${ }^{28}$ FANCE belongs to the Fanconi anaemia complementation group and is mainly responsible for cytogenetic stability and DNA repair. ${ }^{29}$ Moreover, FANCE is associated with sensitivity to platinum drugs in ovarian carcinoma. ${ }^{30}$ To our knowledge, our discovery fills the gap in research on the HRR pathway in UTROSCT, and the results suggest that patients with UTROSCT may also be sensitive to platinum/ PARP inhibitors.

\section{Take home messages}

- Tumours resembling ovarian sex cord tumour (UTROSCT) is a rare type of tumour that requires the combined use of biomarkers and molecular detection for diagnosis.

- Immunohistochemistry showed diffuse and strong expression of B cell lypmphoma-2 (BCL-2) in all patients. BCL-2 overexpression may have potential value in the diagnosis of UTROSCT.

- UTROSCT can have mutations related to the homologous recombination/repair pathway, suggesting the presence of repair gene instability in this tumour type, which is in line with its borderline or malignant behaviour; thus, this tumour may be sensitive to platinum/poly (ADP-ribose) polymerase (PARP) inhibitors.
Contributors SY: Manuscript writing/editing and data collection. JW: Technical assistance and data collection. LY: Technical assistance and manuscript editing. JH: Study concept and design and project development.

Funding This study was financed by the National Natural Science Foundation of China (81872055)

Competing interests None declared.

Patient consent for publication Not required.

Ethics approval Approval was obtained from the ethics committee of the First Affiliated Hospital of USTC (No: 2021-BLK-04).

Provenance and peer review Not commissioned; externally peer reviewed. Data availability statement All data relevant to the study are included in the article

Open access This is an open access article distributed in accordance with the Creative Commons Attribution Non Commercial (CC BY-NC 4.0) license, which permits others to distribute, remix, adapt, build upon this work non-commercially, and license their derivative works on different terms, provided the original work is properly cited, appropriate credit is given, any changes made indicated, and the use is non-commercial. See: http://creativecommons.org/licenses/by-nc/4.0/.

\section{ORCID iD}

Shan Ye http://orcid.org/0000-0001-6496-0893

\section{REFERENCES}

1 de Leval L, Lim GSD, Waltregny D, et al. Diverse phenotypic profile of uterine tumors resembling ovarian sex cord tumors: an immunohistochemical study of 12 cases. Am J Surg Pathol 2010;34:1749-61

2 Hurrell DP, McCluggage WG. Uterine tumour resembling ovarian sex cord tumour is an immunohistochemically polyphenotypic neoplasm which exhibits coexpression of epithelial, myoid and sex cord markers. J Clin Pathol 2007;60:1148-54.

3 Stolnicu S, Balachandran K, Aleykutty MA, et al. Uterine adenosarcomas overgrown by sex-cord-like tumour: report of two cases. J Clin Pathol 2009;62:942-4.

4 Sutak J, Lazic D, Cullimore JE. Uterine tumour resembling an ovarian sex cord tumour. J Clin Pathol 2005;58:888-90

5 Goebel EA, Hernandez Bonilla S, Dong F, et al. Uterine tumor resembling ovarian sex cord tumor (UTROSCT): a morphologic and molecular study of 26 cases confirms recurrent NCOA1-3 rearrangement. Am I Surg Pathol 2020:44:30-42.

6 Heeke AL, Pishvaian MJ, Lynce F, et al. Prevalence of homologous RecombinationRelated gene mutations across multiple cancer types. JCO Precis Oncol 2018;2018. doi:10.1200/P0.17.00286. [Epub ahead of print: 2307 2018].

7 Moore M, McCluggage WG. Uterine tumour resembling ovarian sex cord tumour: first report of a large series with follow-up. Histopathology 2017;71:751-9.

8 Mačák J, Dundr P, Dvořáčková J, et al. Uterine tumors resembling ovarian sex cord tumors (UTROSCT). Report of a case with lymph node metastasis. Cesk Patol 2014;50:46-9

9 Umeda S, Tateno M, Miyagi E, et al. Uterine tumors resembling ovarian sex cord tumors (UTROSCT) with metastasis: clinicopathological study of two cases. Int J Clin Exp Pathol 2014:7:1051-9.

10 Clement PB, Scully RE. Uterine tumors resembling ovarian sex-cord tumors. A clinicopathologic analysis of fourteen cases. Am J Clin Pathol 1976:66:512-25.

11 Meinhold-Heerlein I, Fotopoulou C, Harter P, et al. The new WHO classification of ovarian, fallopian tube, and primary peritoneal cancer and its clinical implications. Arch Gynecol Obstet 2016;293:695-700.

12 Staats PN, Garcia JJ, Dias-Santagata DC, et al. Uterine tumors resembling ovarian sex cord tumors (UTROSCT) lack the JAZF1-JJAZ1 translocation frequently seen in endometrial stromal tumors. Am J Surg Pathol 2009;33:1206-12.

13 Croce $S$, de Kock L, Boshari T, et al. Uterine tumor resembling ovarian sex cord tumor (UTROSCT) commonly exhibits positivity with sex cord markers FOXL2 and SF-1 but lacks FOXL2 and DICER1 mutations. Int J Gynecol Pathol 2016;35:301-8.

14 Dickson BC, Childs TJ, Colgan TJ, et al. Uterine tumor resembling ovarian sex cord tumor: a distinct entity characterized by recurrent NCOA2/3 gene fusions. Am J Surg Pathol 2019;43:178-86.

15 Stewart CJR, Crook M, Tan A. SF1 immunohistochemistry is useful in differentiating uterine tumours resembling sex cord-stromal tumours from potential histological mimics. Pathology 2016;48:434-40

16 Al Harbi R, McNeish IA, El-Bahrawy M. Ovarian sex cord-stromal tumors: an update on clinical features, molecular changes, and management. Int J Gynecol Cancer 2021:31:161-168

17 Wang J, Blakey GL, Zhang L, et al. Uterine tumor resembling ovarian sex cord tumor: report of a case with $t(X ; 6)(p 22.3 ; q 23.1)$ and $t(4 ; 18)(q 21.1 ; q 21.3)$. Diagn Mol Pathol 2003; 12:174-80.

18 Matsuura K, Huang N-J, Cocce K, et al. Downregulation of the proapoptotic protein MOAP- 1 by the UBR5 ubiquitin ligase and its role in ovarian cancer resistance to cisplatin. Oncogene 2017;36:1698-706. 


\section{Original research}

19 Kaur K, Rajeshwari M, Gurung N, et al. Uterine tumor resembling ovarian sex cord tumor: a series of six cases displaying varied histopathological patterns and clinical profiles. Indian J Pathol Microbiol 2020;63:S81-6.

20 Blake EA, Sheridan TB, Wang KL, et al. Clinical characteristics and outcomes of uterine tumors resembling ovarian sex-cord tumors (UTROSCT): a systematic review of literature. Eur J Obstet Gynecol Reprod Biol 2014;181:163-70.

21 Moore M, McCluggage WG. Uterine tumour resembling ovarian sex cord tumour: first report of a large series with follow-up. Histopathology 2017;71:751-9.

22 Telli ML, Chu C, Badve SS, et al. Association of Tumor-Infiltrating Lymphocytes with Homologous Recombination Deficiency and BRCA1/2 Status in Patients with Early Triple-Negative Breast Cancer: A Pooled Analysis. Clin Cancer Res 2020;26:2704-10.

23 Liu YL, Selenica P, Zhou Q, et al. BRCA Mutations, Homologous DNA Repair Deficiency, Tumor Mutational Burden, and Response to Immune Checkpoint Inhibition in Recurrent Ovarian Cancer. JCO Precis Oncol 2020;4. doi:10.1200/PO.20.00069. [Epub ahead of print: 1606 2020].

24 Pilié PG, Gay CM, Byers LA, et al. PARP Inhibitors: Extending Benefit Beyond BRCAMutant Cancers. Clin Cancer Res 2019;25:3759-71.
25 Byers LA, Wang J, Nilsson MB, et al. Proteomic profiling identifies dysregulated pathways in small cell lung cancer and novel therapeutic targets including PARP1. Cancer Discov 2012;2:798-811.

26 Pellegrino B, Mateo J, Serra V, et al. Controversies in oncology: are genomic tests quantifying homologous recombination repair deficiency (HRD) useful for treatment decision making? ESMO Open 2019;4:e480:e000480

27 Nicolas E, Bertucci F, Sabatier R, et al. Targeting BRCA Deficiency in Breast Cancer: What are the Clinical Evidences and the Next Perspectives? Cancers 2018;10. doi:10.3390/cancers10120506. [Epub ahead of print: 1112 2018].

28 Wang $X$, Ran T, Zhang X, et al. 3.9 ̊ structure of the yeast Mec1-Ddc2 complex, a homolog of human ATR-ATRIP. Science 2017;358:1206-9.

29 Fiesco-Roa MO, Giri N, McReynolds LJ, et al. Genotype-Phenotype associations in Fanconi anemia: a literature review. Blood Rev 2019;37:100589.

30 Taniguchi T, Tischkowitz M, Ameziane N, et al. Disruption of the Fanconi anemia-BRCA pathway in cisplatin-sensitive ovarian tumors. Nat Med 2003;9:568-74 